\title{
Fungi isolated from diseased early green fruits and fruits of blueberry (Vaccinium corymbosum L.)
}

\section{Grzyby izolowane z chorych zawiązków owocowych i owoców borówki wysokiej (Vaccinium corymbosum L.)}

\author{
Jan Kućmierz, Jacek Nawrocki, Anna Sojka
}

\section{Summary}

The aim of carried out research was an isolation and identification of fungi from diseased blueberry (Vaccinium corymbosum L.) fruits collected at three dates: during fruit set, maturing of fruit and fruitharvest. In general 14 species and forms of fungi were identified out of 319 isolates. It was quite a significant difference in the communities of microorganisms isolated from fruits in reference to different stages of plant development. Common infection of fruit buds by Botrytis cinerea and Alternaria alternata suggests capability of primary infection during flowering period. Fungi species, which produce toxins, especially genus: Alternaria, Cladosporium, Fusarium and Penicillium present high threat to plants. B. cinerea, Alternaria spp., Colletotrichum gleosporioides and Monilia fructigena have been recognized as particularly dangerous to blueberry crops due to frequency of their occurrence and harmfulness at different stages of fruit development, and long-term character of blueberry production.

Key words: blueberry, fruits, fungi, disease symptoms

\section{Streszczenie}

Celem badań była izolacja i identyfikacja grzybów z chorych owoców borówki wysokiej (Vaccinium corymbosum L.) zebranych w trzech terminach: zawiązywanie owoców, dojrzewanie i podczas pełnej dojrzałości (zbioru) owoców. Ogółem z 319 izolatów zidentyfikowano 14 gatunków i form grzybów. Stwierdzono dość znaczne zróżnicowanie w zbiorowiskach mikroorganizmów izolowanych $z$ owoców $w$ różnej fazie ich rozwoju. Powszechne zasiedlanie zawiązków owocowych przez Botrytis cinerea i Alternaria alternata sugeruje możliwość infekcji pierwotnej w okresie kwitnienia roślin. Duże zagrożenie stanowią toksynotwórcze grzyby rodzajów: Alternaria, Cladosporium, Fusarium i Penicillium. Ze względu na częstotliwość występowania i szkodliwość w różnych fazach rozwoju owoców oraz wieloletni charakter uprawy borówki wysokiej, za szczególnie niebezpieczne dla upraw tej rośliny należy uznać: B. cinerea, Alternaria spp., Colletotrichum gleosporioides oraz Monilia fructigena.

Słowa kluczowe: borówka wysoka, owoce, grzyby, objawy chorobowe

\footnotetext{
Uniwersytet Rolniczy im. Hugona Kołłątaja w Krakowie

Katedra Ochrony Roślin

Al. 29 Listopada 54, 31-425 Kraków

j.nawrocki@ogr.ur.krakow.pl
} 


\section{Wstęp / Introduction}

Borówkę wysoką (Vaccinium corymbosum L.) uprawia się w Polsce na coraz większą skalę i to zarówno pod względem powierzchni plantacji (nawet 10 i 20 hektarowe na Lubelszczyźnie), jak i wzrastającej liczby producentów. W miarę wzrostu powierzchni upraw i starzenia się plantacji pojawiają się problemy z chorobami i szkodnikami tej rośliny (Łabanowska i wsp. 1987; MachowiczStefaniak i Zalewska 2001; Bryk 2010; Łabanowska 2010). Dotychczas ukazało się kilka prac dotyczących chorób grzybowych pędów i liści (Borecki i Pliszka 1978; Machowicz-Stefaniak i Zalewska 2001; Szmagara 2005; Szmagara i wsp. 2006; Bryk 2010), jednak niewiele prac opublikowano na temat zdrowotności owoców borówki z Lubelszczyzny (Zalewska i wsp. 2007) i Skierniewic (Meszka i Bielenin 2012).

Celem pracy było podjęcie badań nad zdrowotnością zawiązków owocowych i owoców borówki wysokiej w okolicach Krakowa.

\section{Materiały i metody / Materials and methods}

W latach 2008 i 2009 przeprowadzono badania nad zdrowotnością owoców 11 odmian borówki wysokiej, na prywatnej plantacji o powierzchni 1 ha w okolicach Krakowa. Na plantacji nie były stosowane środki do zwalczania chorób, szkodników i chwastów. Badane odmiany to: Bluetta i Sunrise o wczesnej porze dojrzewania, Bluejay, Blueray, Bluecrop, Bonifacy, Croatian i Puru o średniej porze dojrzewania oraz Brigitta, Darrow i Jersey o późnej porze dojrzewania. Ocenę zdrowotności zawiązków owocowych i owoców borówki wysokiej przeprowadzono $\mathrm{w}$ trzech terminach: w czasie opadania kwiatów i tworzenia się zawiązków owocowych (trzecia dekada maja), w czasie rozpoczęcia dojrzewania owoców (pierwsza dekada lipca) i w czasie pełnej dojrzałości owoców (pierwsza dekada sierpnia). Zawiązki owoców, a później owoce z objawami chorobowymi, po 5 dla każdej odmiany i w każdym $\mathrm{z}$ terminów, pobrano do makroi mikroskopowych badań laboratoryjnych. Obecność grzybów i ich identyfikację określano na podstawie oznak etiologicznych oraz izolacji i hodowli kultur na sztucznych podłożach agarowych. Określano także ilość izolatów z poszczególnych prób, przeliczając je na procentowy udział w odniesieniu do ogółu zbiorowiska.

\section{Wyniki i dyskusja / Results and discussion}

Podczas przeprowadzonych badań, na wszystkich 11 odmianach stwierdzono zawiązki owoców lub owoce z objawami chorobowymi, przy dość znacznym zróżnicowaniu w przypadku poszczególnych odmian. Z chorych owoców wyosobniono 319 izolatów (w obu latach badań), z których zidentyfikowano 14 gatunków i form grzybów. Już wstępne analizy mikologiczne wskazały na dużą bioróżnorodność grzybów zasiedlających chore owoce, nie stwierdzono prób tylko $\mathrm{z}$ jednym wyizolowanym gatunkiem grzyba.
Zidentyfikowano stosunkowo najmniej form grzybów z zawiązków owocowych (rys. 1). Najczęściej izolowano Botrytis cinerea, bo aż $43,8 \%$ wszystkich izolatów oraz Alternaria alternata - 24,6\%, co sugeruje o możliwości infekcji pierwotnej w okresie kwitnienia, zwłaszcza pierwszego z nich, znanego $\mathrm{z}$ takich infekcji w przypadku innych roślin, np. truskawek. Grzyby te izolowano prawie ze wszystkich odmian $B$. cinerea $\mathrm{z}$ wyjątkiem odmiany Brigitta, a $A$. alternata $\mathrm{z}$ wyjątkiem odmian Sunrise i Bonifacy. Z owoców odmiany Bluejay izolowano wszystkie zidentyfikowane gatunki grzybów (tab. 1).

Z owoców w okresie dojrzewania i pełnej dojrzałości izolowano i za szczególnie niebezpieczne uznano grzyby: B. cinerea (30,7\%), Alternaria spp. (35,2\%), Penicillium spp. (6,1\%) oraz Fusarium spp. (5,4\%) (tab. 2, rys. 1). $\mathrm{O}$ podobnych spostrzeżeniach donoszą MachowiczStefaniak i Zalewska (2001), Szmagara i wsp. (2006) oraz Bryk (2010). W sprzyjających warunkach dla rozwoju chorób, groźne dla uprawy borówki mogą okazać się grzyby: Colletotrichum gloeosporioides, Monilia fructigena i Sclerotinia spp., choć tego ostatniego grzyba w przeprowadzonych doświadczeniach nie izolowano (Machowicz-Stefaniak i Zalewska 2001; Meszka i Bielenin 2012). Na uwage zasługują takie grzyby, jak: Cladosporium cladosporioides i Epicoccum nigrum (syn. E. purpurascens) dość często wyosabniane, wśród innych, z chorych owoców, a które mogą się okazać saprobiontami ograniczającymi wzrost patogenów i wspomagać naturalną ochronę biologiczną przed nimi (Szmagara i wsp. 2006). Sa jednak także doniesienia, że grzyby te w odpowiednich warunkach mogą być patogenicznymi i współuczestniczyć w procesach chorobowych, np. gniciu korzeni marchwi (Kućmierz 1990), czy zgorzelach siewek (Kućmierz i Gorajczyk 1991; Kućmierz i Mazur 2003; Kućmierz i Sumera 2009).

Odmianami, z których izolowano najwięcej gatunków grzybów były: Bluecrop, Darrow oraz Jersey (11), zaś najmniej z odmian Bonifacy (7) i Brigitta (6). A. alternata najczęściej izolowano z odmian Bluejay (25,8\% izolatów) i Brigitta (33,3\%), a najmniej izolatów uzyskano z odmian Croatian (5,6\%) i Darrow (7,4\%). Grzyb B. cinerea najliczniej izolowany był z odmiany Blueray $(41,7 \%)$, zaś najmniej licznie $\mathrm{z}$ odmiany Darrow $(14,8 \%)$. Z kolei Fusarium spp. najczęściej izolowano $\mathrm{z}$ odmian Blueray $(12,5 \%)$ i Darrow $(11,1 \%)$, a z odmian Bluetta i Bluejay w ogóle go nie izolowano.

Ze zdeformowanych i zamierających zawiązków owocowych najczęściej izolowano $B$. cinerea i $A$. alternata. Wśród owoców z objawami chorobowymi, najczęściej stwierdzono zgnilizny, z których izolowano A. alternata, B. cinerea, C. gloeosporioides, Fusarium spp. i Phomopsis archeri. Z kolei z owoców ze spękaniami i antraknozą izolowano: C. gloeosporioides i P. archeri. Dość często obserwowano na owocach szare lub ciemnobrunatne, suche plamy (Phoma exiqua) lub plamy prawie czarne (Alternaria spp., C. cladosporioides), natomiast mumifikacji i opadaniu owoców najczęściej towarzyszył grzyb $M$. fructigena (tab. 3). Pojedyncze izolaty T. myrtilli i $P$. archeri uzyskane $\mathrm{z}$ owoców wynikają prawdopodobnie $\mathrm{z}$ powszechnego występowania tych grzybów na pędach borówki z objawami zgorzelowymi (Szmagara i wsp. 


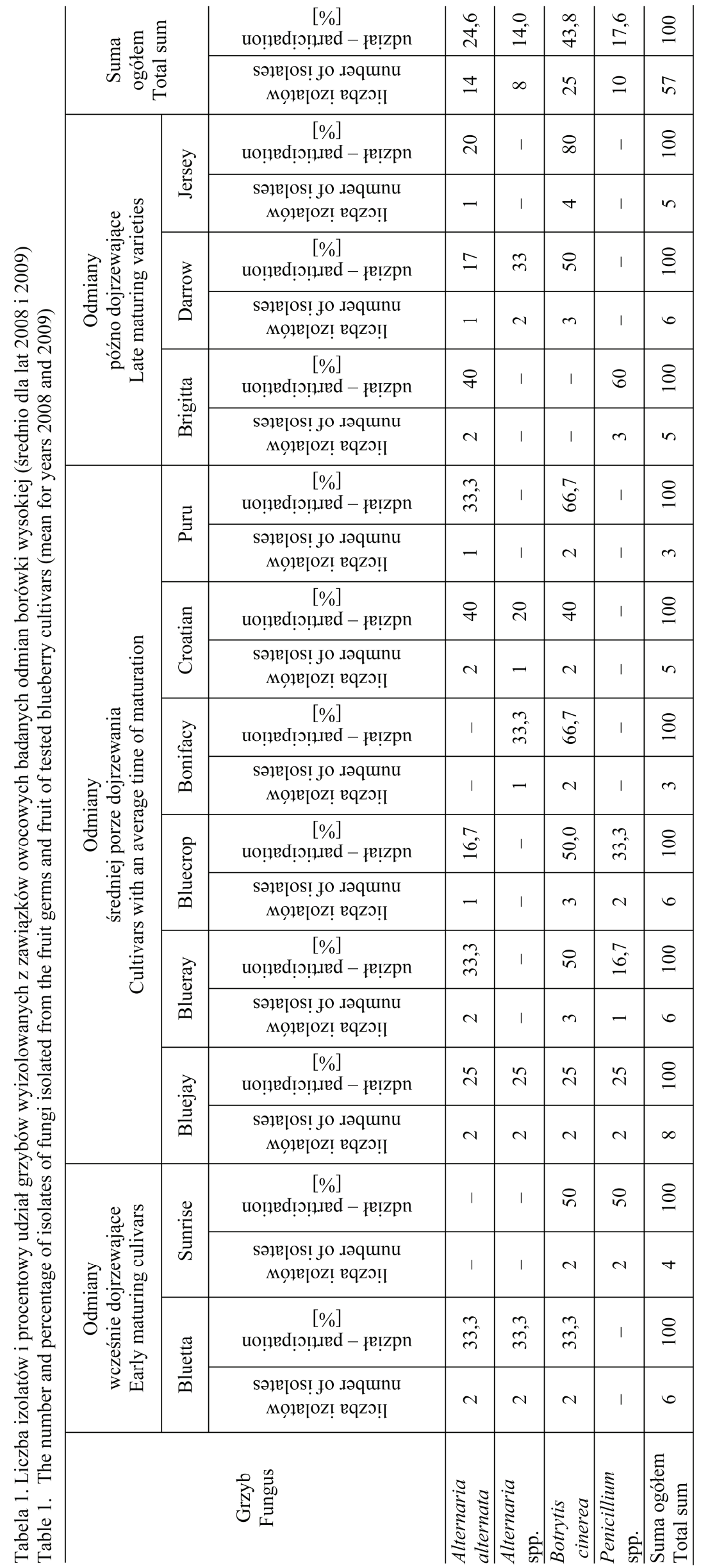




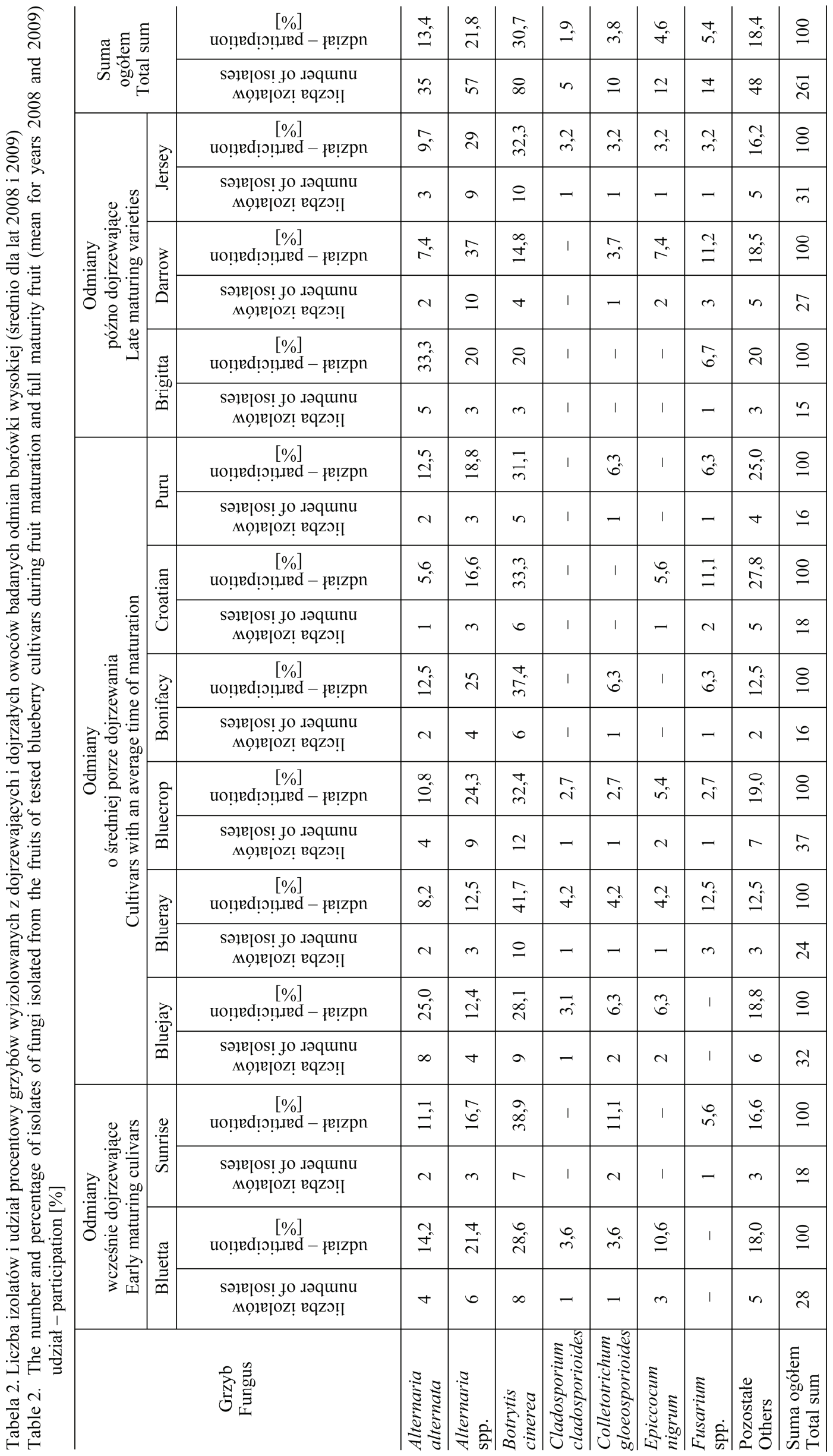


Tabela 3. Grzyby najczęściej izolowane z zawiązków owocowych i owoców borówki wysokiej, wykazujących typowe objawy chorobowe

Table 3. Fungi the most frequently isolated from blueberry fruit germs and fruits, showing typical disease symptoms

\begin{tabular}{|c|c|c|c|c|c|c|}
\hline $\begin{array}{l}\text { Grzyb } \\
\text { Fungus }\end{array}$ & $\begin{array}{l}\text { Zawiazki owocowe, } \\
\text { których kwiaty ulegały } \\
\text { zgorzeli, brunatniały } \\
\text { i zasychały } \\
\text { Fruit germs, } \\
\text { which flowers } \\
\text { underwent gangrene, } \\
\text { browning and dried up }\end{array}$ & $\begin{array}{c}\text { Gnicie } \\
\text { owoców } \\
\text { Rotting } \\
\text { fruit }\end{array}$ & $\begin{array}{l}\text { Antraknoza, } \\
\text { spękania } \\
\text { Anthracnose, } \\
\text { cracks }\end{array}$ & $\begin{array}{c}\text { Plamy szare, } \\
\text { ciemnobrunatne } \\
\text { lub brunatne, suche } \\
\text { Stains gray, } \\
\text { dark brown } \\
\text { or brown, dry }\end{array}$ & $\begin{array}{c}\text { Plamy } \\
\text { ciemnobrunatne } \\
\text { lub prawie czarne } \\
\text { Stains dark brown } \\
\text { or almost black }\end{array}$ & $\begin{array}{l}\text { Mumifikacja } \\
\text { i przedwczesne } \\
\text { opadanie } \\
\text { owoców } \\
\text { Mummification } \\
\text { and premature } \\
\text { fruit drop }\end{array}$ \\
\hline \multicolumn{7}{|l|}{ Alternaria alternata } \\
\hline \multicolumn{7}{|l|}{ Alternaria spp. } \\
\hline \multicolumn{7}{|l|}{ Botrytis cinerea } \\
\hline \multicolumn{7}{|l|}{$\begin{array}{l}\text { Cladosporium } \\
\text { cladosporioides }\end{array}$} \\
\hline \multicolumn{7}{|l|}{$\begin{array}{l}\text { Colletotrichum } \\
\text { gloeosporioides }\end{array}$} \\
\hline \multicolumn{7}{|l|}{ Epiccocum nigrum } \\
\hline \multicolumn{7}{|l|}{ Fusarium spp. } \\
\hline \multicolumn{7}{|l|}{ Monilia fructigena } \\
\hline \multicolumn{7}{|l|}{ Penicillium spp. } \\
\hline \multicolumn{7}{|l|}{ Phoma exigua } \\
\hline \multicolumn{7}{|l|}{ Phomopsis archeri } \\
\hline \multicolumn{7}{|c|}{ Polistigma ochraceum } \\
\hline \multicolumn{7}{|l|}{ Saccharomyces spp. } \\
\hline Topospora myrtilli & & & & & & \\
\hline
\end{tabular}

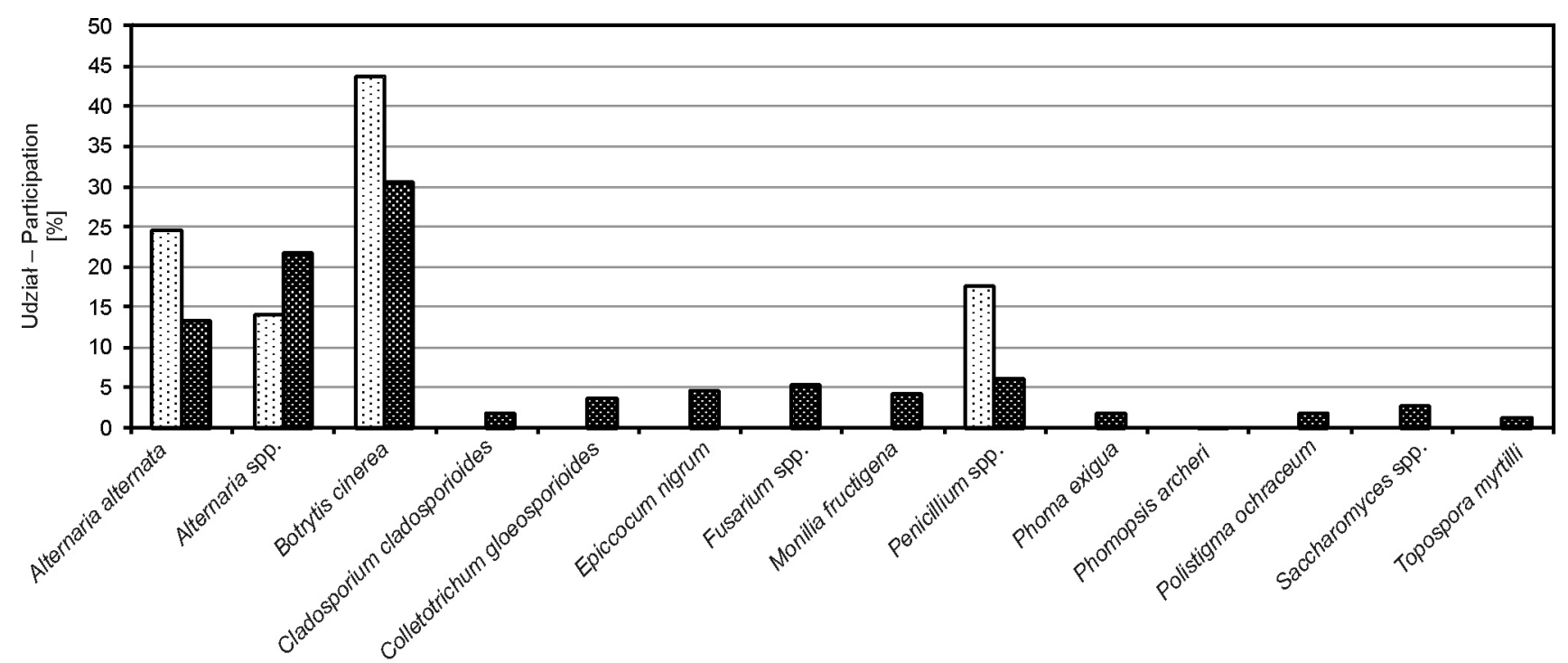

- Okres opadania kwiatów i tworzenie się zawiązków owoców - Period of falling flowers and fruit set formation

- Okres dojrzewania owoców oraz pełnej dojrzałości owoców - Ripening period and the full maturity of fruit

Rys. 1. Procentowy udział grzybów wyizolowanych z zawiązków owocowych i owoców borówki wysokiej

Fig. 1. The percentage of fungi isolated from the blueberry fruit germs and fruits

2006). Pewne zagrożenie dla konsumentów jagód borówki wysokiej stanowią izolowane $\mathrm{z}$ owoców grzyby toksyno- twórcze rodzajów: Alternaria, Cladosporium, Fusarium i Penicillium. 


\section{Wnioski / Conclusions}

1. W procesie chorobowym owoców borówki wysokiej bierze udział zespół grzybów, wśród których są zarówno typowe patogeny, jak i saprotrofy.

2. Udział poszczególnych mikroorganizmów w procesie chorobowym zależny jest od odmiany oraz fazy rozwojowej owoców.

3. Główni sprawcy chorób decydują o zróżnicowanych typach objawów chorobowych.
4. Niebezpiecznymi dla konsumentów jagód są izolowane z nich grzyby toksynotwórcze rodzajów: Alternaria, Botrytis, Cladosporium, Fusarium i Penicillium.

5. Ze względu na częstotliwość izolacji, szkodliwość w różnych fazach rozwoju owoców oraz wieloletni charakter uprawy borówki wysokiej, za szczególnie niebezpieczne dla uprawy tej rośliny, zwłaszcza dla owoców, należy uznać: Alternaria spp., B. cinerea, C. gloeosporioides i M. fructigena.

\section{Literatura / References}

Borecki Z., Pliszka K. 1978. Zgorzel pędów borówki wysokiej wywołana przez grzyb Gordonia cassandre (Pedic.) Groves. Acta Agrobot. 30 (1/2): 159-171.

Bryk H. 2010. Choroby występujące na plantacjach borówki wysokiej. s. 54-58. W: Materiały Ogólnopolskiej Konferencji Nauka Praktyce „Intensyfikacja uprawy krzewów jagodowych przez wdrażanie najnowszych wyników badań”. Skierniewice ISiK, 20-21 kwietnia 2010, 97 ss.

Kućmierz J. 1990. The pathogenicity of some fungal species for carrot roots. Patolog. Fyzjol. Rostin, U.E.B.E. SAV: $334-434$.

Kućmierz J., Gorajczyk S. 1991. Pathogenicity of fungi isolated from sowing material of perennial ryegrass (Lolium perenne L.) for germinating caryopses and seedlings. Phytopathol. Pol. 1 (13): 62-65.

Kućmierz J., Mazur S. 2003. Grzyby izolowane z nasion brokuła (Brassica oleracea var. italica) oraz patogeniczność wybranych gatunków grzybów dla siewek. Folia Hortic. 1: 568-570.

Kućmierz J., Sumera R. 2009. Grzyby izolowane z nasion oberżyny (Solanum melongena L.) oraz patogeniczność wybranych gatunków grzybów dla siewek i próby ich zwalczania. [Fungi isolated from eggplant (Solanum melongena L.) seeds, their pathogenicity to seedlings and attempts of their control]. Prog. Plant Prot./Post. Ochr. Roślin 49 (1): 219-223.

Łabanowska B. 2010. Szkodniki borówki wysokiej i możliwości ich zwalczania. s. 59-64. W: Materiały Ogólnopolskiej Konferencji Nauka Praktyce „Intensyfikacja uprawy krzewów jagodowych przez wdrażanie najnowszych wyników badań”. ISiK, Skierniewice, 20-21 kwietnia 2010, 97 ss.

Łabanowska B., Bielenin A., Cinciara T. 1987. Ochrona plantacji roślin jagodowych. PWRiL, Warszawa: 268-282.

Machowicz-Stefaniak Z., Zalewska E. 2001. Grzyby zasiedlające nadziemne organy borówki wysokiej - Vaccinum corymbosum L. s. 213-215. W: Materiały Ogólnopolskiej Naukowej Konferencji Ochrony Roślin Sadowniczych. ISiK, Skierniewice, 22-23 luty 2001,259 ss.

Meszka B., Bielenin A. 2012. Antraknoza borówki wysokiej, występowanie, szkodliwość i możliwości zwalczania. [Bluberry anthracnose, occurrence, harmfulness and control possibilities]. Prog. Plant Prot./Post. Ochr. Roślin 52 (1): 88-91.

Szmagara M. 2005. Występowanie i etiologia chorób pędów borówki wysokiej (Vaccinium corymbosum L.) uprawianej w południowowschodniej Polsce. Praca doktorska, AR Lublin, 80 ss.

Szmagara M., Zalewska E., Machowicz-Stefaniak Z. 2006. Choroby występujące na nadziemnych organach borówki wysokiej (Vaccinium corymbosum L.). s. 86-92. W: Materiały Międzynarodowej Konferencji „Uprawa borówki i żurawiny”. ISiK, Skierniewice, 19-22 czerwca 2006, 262 ss.

Zalewska E., Król E., Machowicz-Stefaniak Z. 2007. Grzyby zasiedlające owoce borówki wysokiej (Vaccinium corymbosum L.) uprawianej w południowo-wschodniej Polsce. [Fungi colonizing the fruits of blueberry (Vaccinium corymbosum L.) cultivated in south-eastern Poland]. Prog. Plant Prot./Post. Ochr. Roślin 47 (2): 380-384. 